\title{
Factors associated with human papillomavirus infection - findings from a cervical cancer screening program for female employees in Beijing
}

This article was published in the following Dove Press journal: Cancer Management and Research

\section{Hui-xia Yang \\ Yu Zhong \\ Wei-hua Lv \\ Hong Yu}

Labor Model Health Management Center, Beijing Rehabilitation Hospital, Capital Medical University, Beijing, People's Republic of China
Correspondence: Hong Yu Labor Model Health Management Center, Beijing Rehabilitation Hospital, Capital Medical University, Xixiazhuang, Badachu, Shijingshan District, Beijing I00I44, People's Republic of China

$\mathrm{Tel}+86 \quad 05698 \quad$ II3I

Fax +86 $105698 \quad \mid 131$

Email y_hong@aliyun.com
Background: In 2018, the Beijing Federation of Trade Unions organized a cervical cancer screening program for female employees for the first time. This study aimed to investigate the screening results of this program and determine the factors associated with human papillomavirus (HPV) infection.

Methods: A total of 8297 female employees participating in the screening program between January 1, 2018, and December 31, 2018, were enrolled in this study. The methods for screening cervical cancer included ThinPrep cytology test (TCT) and HPV genotyping test. Single-factor analysis and multiple binary logistic regression analysis were used to identify the factors associated with HPV infection.

Results: Of the 8297 women (median age: 43.00 years), TCT was found to be abnormal in 116 patients (1.40\%) and 1169 (14.09\%) were positive for HPV genotyping test. Notably, HPV-52 was the most prevalent subtype (3.05\%), followed by HPV-16 (2.82\%), HPV-58 (2.01\%), HPV-51 $(1.58 \%)$ and HPV-56 (1.49\%). Multivariate logistic regression analysis revealed that taxi drivers $(\mathrm{OR}=1.98 ; 95 \% \mathrm{CI}=1.31-2.99)$ and single women with a history of sexual activity $(\mathrm{OR}=2.32$; 95\% CI $=1.41-3.82$ ) were significantly associated with an increased risk of HPV infection $(P<0.05)$, whereas medical workers $(\mathrm{OR}=0.67 ; 95 \% \mathrm{CI}=0.51-0.88)$ and factory workers $(\mathrm{OR}$ $=0.36 ; 95 \% \mathrm{CI}=0.17-0.77)$ were protective factors for HPV infection $(P<0.05)$.

Conclusion: HPV-52, HPV-16 and HPV-58 are the most common types of high-risk HPV among female employees in Beijing. Being taxi drivers and single women with a history of sexual activity are significantly associated with the risk of HPV infection.

Keywords: cervical cancer screening, HPV types, cervical cytology, occupation, Beijing

\section{Plain language summary}

In 2018, the Beijing Federation of Trade Unions firstly organized a targeted cervical cancer screening program for female employees in Beijing. A total of 8297 female employees participating in the screening program were enrolled in this study. This program aims to investigate the overall cervical cancer screening results and identify the factors correlated with HPV infection using the single-factor analysis and multiple binary logistic regression analysis. The results of these analyses reveal that:

- HPV-52, HPV-16 and HPV-58 are the three most frequently detected HPV subtypes among the female employees participated in this cervical cancer screening program. This merits concern in the primary and secondary cervical cancer prevention among female employees in Beijing.

- HPV infection is associated with marital status and occupation. Being medical workers and factory workers is protective against HPV infection. Female taxi drivers and single 
women with sexual experiences are more likely to suffer from HPV infection. Therefore, more opportunities are needed by them to receive health education on HPV prevention and routine cervical cancer screening.

\section{Introduction}

Cervical cancer is one of the most common malignant cancers in women, with 570,000 annual cases and 311,000 deaths in 2018 worldwide. ${ }^{1}$ According to the China National Cancer Center, there are approximately 100,000 new diagnoses and 30,000 deaths from cervical cancer every year. High-risk human papillomavirus (HPV) is a key cause of cervical cancer, which has been implicated in $99.7 \%$ of cervical squamous cell cancer cases worldwide. ${ }^{2,3}$ Therefore, launching a cervical cancer screening program is an effective means of reducing the disease incidence and mortality. In the past, numerous risk factors have been identified to be associated with the development of cervical cancer, including age, ethnicity, early marriage, multiple sexual partners, poor genital hygiene, history of abortions, multiparity, oral contraceptive use, tobacco smoking and low socioeconomic status. ${ }^{4}$ However, there have been few studies on the relationship between HPV infection and particular occupations. In 2018, the Beijing Federation of Trade Unions organized a cervical cancer screening program for female employees in Beijing. This study examined the results from the screening process of this program and established the association between HPV infection and its potential factors, especially with regard to various kinds of occupations, including those of taxi drivers, medical workers, teachers, personnel belonging to authority units and institutions, and sanitation and factory workers. To the best of our knowledge, this was the first cervical cancer screening program for female employees organized by the Beijing Federation of Trade Unions. The overall screening results of this program were compiled from January 1, 2018, to December 31, 2018, and our analyses could extend the existing knowledge on the subject, which is novel for female workers in Beijing. In addition, the findings of this study would provide the basis for design of HPV vaccine and cervical cancer prevention policies for the local area.

\section{Methods}

\section{Study design}

A cervical cancer screening program was launched for female workers in Beijing, which was managed by the Beijing Federation of Trade Unions together with Beijing Rehabilitation Hospital. Female workers from Beijing who volunteered for this program and who met the inclusion and exclusion criteria were enrolled for the period beginning January 1, 2018, until December 31, 2018, and underwent testing at the Beijing Rehabilitation Hospital. The Labor Model Health Management Center of Beijing Rehabilitation Hospital was responsible for sending text messages and making phone calls to every female participant with positive screening results and advising them to perform further diagnosis and treatment at the gynecological outpatient department. The study protocol was approved by the Ethical Committee of Beijing Rehabilitation Hospital.

\section{Patient recruitment}

The information of this screening program was conveyed to the trade union members by Beijing Federation of Trade Unions. A total of 9000 female workers of the trade union in Beijing were invited to participate in this screening program at the Beijing Rehabilitation Hospital. The inclusion criteria included the following: (i) healthy women without cervical lesions, (ii) history of sexual activity and (iii) current employment with the Beijing municipality. Exclusion criteria included the following: (i) pregnant at the time of screening, (ii) history of hysterectomy or cervical conization and (iii) participated in a similar program within the same year.

\section{Screening procedures}

After obtaining written informed consent, the eligible participants were asked to complete a baseline questionnaire regarding age, occupation (taxi driver, medical worker, teacher, personnel from authority units and institutions, sanitation workers and factory workers), menstrual status (normal menstruation, irregular menstruation and menopause) and marital status (sexually active single and married). Specifically, the term "medical worker" was used to indicate clinicians, nurses, biomedical scientists and medical technicians. Subsequent to the questionnaire, the participants underwent a thorough gynecological examination conducted by an experienced gynecologist, together with a ThinPrep cytology test (TCT) and a HPV genotyping test. TCT and HPV test were conducted successively on each participant at the same time.

\section{Sample collection and storage}

Cervical specimen was collected using a plastic cytology brush, placed in a vial containing preservation medium and then stored at $4^{\circ} \mathrm{C}$. The preservation medium for 
TCT consisted of $10 \mathrm{~mL}$ phosphate-buffered saline and absolute ethanol, while $3 \mathrm{~mL}$ of isotonic sodium chloride was used as the preservation medium for HPV genotyping test, according to the protocols of Xiangshu $\mathrm{Bio}^{\circledR}$ Cell Preservation Liquid (Beijing: XiangshuBio, Inc., China) and Yaneng Bio $^{\circledR}$ Human Papillomavirus Preservation (Shenzhen: YanengBio, Inc., China).

\section{TCT}

All samples were subjected to TCT (Oak Hengye Bio, Beijing, China). The results of cervical cytology smears were interpreted by qualified pathologists at Beijing Rehabilitation Hospital in accordance with the 2001 Bethesda System terminology. ${ }^{5}$ Cervical cytology data were classified as previously described. ${ }^{5}$

\section{HPV genotyping test}

The identification of HPV genotypes was performed using YanengBio $^{\circledR}$ Human Papillomavirus Genotyping Kit (Shenzhen: YanengBio, Inc., China) according to the manufacturer's instructions. Fifteen HPV types included 13 high-risk types (HPV-16, HPV-18, HPV-31, HPV-33, HPV-35, HPV-39, HPV-45, HPV-51, HPV-52, HPV-56, HPV-58, HPV-59 and HPV-68) and two low-risk types (HPV-6 and HPV-11) were detected. Based on the information provided by YanengBio $^{\circledR}$ Human Papillomavirus Genotyping Kit (Shenzhen: YanengBio, Inc., China), the sensitivity and specificity of this test were at least $1.0 \times 10^{3}$ copies/mL of HPV load per sample and more than $98 \%$, respectively.

\section{Statistical analysis}

All data were analyzed using SPSS version 22 (SPSS Inc.; Illinois, USA). Descriptive statistics were used to analyze the demographic characteristics of all participants and their screening results including HPV distribution, frequencies of HPV positivity and cytology results. Quantitative data were described using mean and standard deviation (SD), or median and interquartile range (IR) if the data did not follow a normal distribution. Kolmogorov-Smirnov test was used to evaluate whether the data were normally distributed. Qualitative data were presented as frequencies and percentages. Single-factor analysis such as chi-square test was performed to compare the differences between HPV-positive group and HPV-negative group with respect to age, menstrual status, occupation and marital status. To identify the factors associated with HPV infection, multiple binary logistic regression analysis was carried out over the four variables. During the data analysis, there were no missing data on any of the measures, and therefore, procedures for handling missing data were not followed. $P$ values of less than 0.05 were considered statistically significant.

\section{Results}

\section{Demographic characteristics and overall screening results}

There were 8369 female workers participated in this screening program, with a response rate of $92.99 \%$ (8369/9000). Following the exclusion of 15 pregnant subjects at the time of screening and 57 subjects with a history of hysterectomy or cervical conization, a total of 8297 female workers were enrolled in this study. As shown in Figure 1, the median age of all eligible participants was 43.00 years (IR: 36.00-51.00). Table 1 summarizes the demographic characteristics and overall screening results of the study population. Among these 8297 participants, $1.40 \%$ (116/8297) had abnormal TCT results, and 14.09\% (1169/8297) were positive for HPV genotyping test.

\section{The prevalence and distribution of HPV subtypes}

The overall HPV positivity rate of total participants was $14.09 \%$. The five most prevalent high-risk subtypes among these cases were HPV-52, HPV-16, HPV-58, HPV-51 and HPV-56, with frequencies of 3.05\%, 2.82\%, 2.01\%, 1.58\% and $1.49 \%$, respectively (Figure 2 ).

\section{The factors associated with HPV infection}

Through single-factor analysis, we found that the HPV-positive rates among different occupation types $\left(\chi^{2}=29.73, P<0.05\right)$ and different marital status $\left(\chi^{2}=15.07\right.$, $P<0.05)$ were significantly different. However, no significant differences were observed for different age groups and different menstrual statuses (Table 2).

Through multiple binary logistic regression analysis, we found that taxi drivers, medical workers, factory workers and single women with a history of sexual activity were significantly associated with HPV infection. As shown in Table 3, the ORs (95\% CIs) of taxi drivers, medical workers, factory workers and single women with a history of sexual activity were 1.98 (1.31-2.99), 0.67 $(0.51-0.88), \quad 0.36 \quad(0.17-0.77)$ and $2.32 \quad(1.41-3.82)$, respectively $(P<0.05)$. 


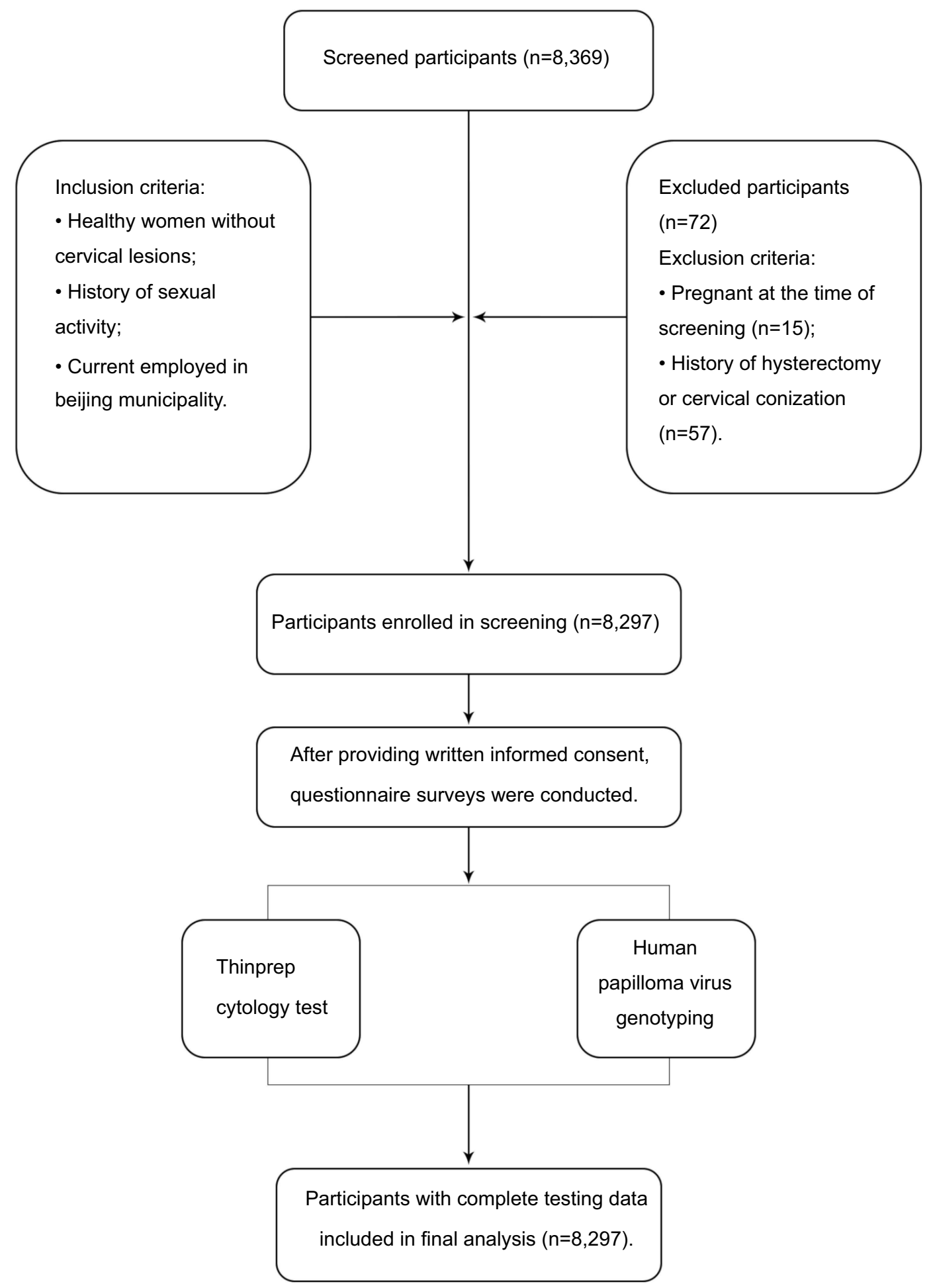

Figure I Flow diagram of screened, enrolled and tested participants.

\section{Discussion}

\section{Overall screening results}

The findings of this screening program revealed that the overall cervical cytological abnormality rate was 1.4\% (116/8297), lower as compared to the rates reported in certain areas of
China. ${ }^{6,7}$ This may be due to the fact that the participants in this program are mostly healthy women, or due to the consequences of regular cervical cancer screening in the past.

Our results also indicated that the overall prevalence rate of HPV infection among female employees 
Table I Demographic characteristics and the overall screening results

\begin{tabular}{|c|c|}
\hline Characteristics & $\begin{array}{l}\text { Total participants } \\
(\mathrm{n}, \%)\end{array}$ \\
\hline \multicolumn{2}{|l|}{ Age (years) } \\
\hline$<25$ & $45(0.54 \%)$ \\
\hline $25-34$ & $1695(20.43 \%)$ \\
\hline $35-44$ & 2708 (32.64\%) \\
\hline $45-54$ & $2452(29.55 \%)$ \\
\hline $55-64$ & 997 (12.02\%) \\
\hline$\geq 65$ & $400(4.82 \%)$ \\
\hline \multicolumn{2}{|l|}{ Occupation } \\
\hline Personnels from authority units and institutions & 5898 (71.09\%) \\
\hline Taxi drivers & $132(1.59 \%)$ \\
\hline Factory workers & $134(1.62 \%)$ \\
\hline Sanitation workers & 744 (8.97\%) \\
\hline Teachers & 744 (8.97\%) \\
\hline Medical workers & $645(7.77 \%)$ \\
\hline \multicolumn{2}{|l|}{ Menstrual status } \\
\hline Normal menstruation & $5704(68.75 \%)$ \\
\hline Irregular menstruation & $560(6.75 \%)$ \\
\hline Menopause & $2033(24.50 \%)$ \\
\hline \multicolumn{2}{|l|}{ Marital status } \\
\hline Single but with a history of sexual activity & $88(1.06 \%)$ \\
\hline Married & 8209 (98.94\%) \\
\hline \multicolumn{2}{|l|}{ TCT } \\
\hline NILM & $8181(98.60 \%)$ \\
\hline ASC-US/AGC & $26(0.31 \%)$ \\
\hline ASC-H & $15(0.18 \%)$ \\
\hline LSIL & $51(0.61 \%)$ \\
\hline HSIL & $23(0.28 \%)$ \\
\hline SCC & $\mathrm{I}(0.0 \mathrm{I} \%)$ \\
\hline \multicolumn{2}{|l|}{ HPV genotyping test } \\
\hline Negative & 7128 (85.9।\%) \\
\hline Positive & $1169(14.09 \%)$ \\
\hline HR only & $1078(12.99 \%)$ \\
\hline LR only & $55(0.66 \%)$ \\
\hline$H R \& L R$ & $36(0.43 \%)$ \\
\hline \multicolumn{2}{|l|}{ Multiple infections } \\
\hline I type & $912(10.99 \%)$ \\
\hline 2 types & 195 (2.35\%) \\
\hline 3 types & $44(0.53 \%)$ \\
\hline 4 types & $12(0.14 \%)$ \\
\hline 5 types & 2 (0.02\%) \\
\hline 6 types & $2(0.02 \%)$ \\
\hline 7 types & I (0.0I\%) \\
\hline 9 types & I (0.01\%) \\
\hline
\end{tabular}

Abbreviations: N, number; TCT, thinPrep cytology test; NILM, negative for intraepithelial lesions or malignancy; ASC-US, atypical squamous cells of undetermined significance; AGC, atypical glandular cells; LSIL, low-grade squamous intraepithelial lesion; HSIL, high-grade squamous intraepithelial lesion; ASC-H, atypical squamous cells-cannot exclude HSIL; SCC, squamous cell carcinoma; HPV, human papillomavirus; $H R$, high risk; LR, low risk. in Beijing was $14.09 \%(1169 / 8297)$. The prevalence rate of high-risk HPV infection was $12.99 \%$ (1078/ 8297), while that of low-risk HPV was $0.66 \%(55 /$ 8297). The prevalence rate of female participants with both high- and low-risk HPV infection was $0.43 \%$ (36/ 8297). Wang et $\mathrm{al}^{8}$ studied the HPV genotype distribution and nationwide HPV prevalence in China and reported an overall positivity rate of $21.07 \%$ (range: 18.42-31.94\%) for high-risk HPV, varying by area. These divergent rates may be attributed to genetic variation, sexual behavior and biological predisposition. $^{9}$

\section{The distribution of HPV}

In the present study, HPV-52 was the most common subtype and HPV-16 was the second most frequent subtype of HPV infection. These findings are consistent with the data reported in Guangzhou, Shenzhen, Changsha, Shanghai and Wuxi cities, ${ }^{10-14}$ while the most frequent subtype in Chengdu and Liaoning cities is HPV-16. ${ }^{15,16}$ Sanjosé et $\mathrm{al}^{16}$ also found that HPV-16 is the most common subtype of HPV infection worldwide, except for East Africa, Japan and Taiwan. This may be due to the fact that the distribution and prevalence of HPV are varied among different areas. ${ }^{17}$ Moreover, this program is a targeted populationbased screening, which largely differs from the opportunistic screening of outpatients. Although the prevalence of HPV-16 was lower than that of HPV-52 in this study, earlier studies found that HPV-16 was the most common and pathogenic subtype identified among cervical cancer patients and tended to cause persistent infection as well as neoplastic progression. ${ }^{18-20}$ Therefore, HPV-16 deserves specific attention in the prevention of cervical cancer.

In addition, HPV-58 was the third-most frequent subtype, after HPV-52 and HPV-16. These results are consistent with those of a previous study indicating that HPV-52 and HPV-58 were the predominant HPV subtypes in China. ${ }^{21}$ At present, there are four types of vaccines available to protect against HPV infection, including monovalent vaccine (HPV-16), bivalent vaccine (HPV-16 and HPV-18), quadrivalent vaccine (HPV-16, HPV-18, HPV-6 and HPV-11) ${ }^{22}$ and nonavalent vaccine (HPV-16, HPV-18, HPV-6, HPV-11, HPV-31, HPV-33, HPV-45, HPV-52 and HPV-58). ${ }^{23}$ It is speculated that the addition of HPV-52 and HPV-58 in the vaccine may provide a higher or enhanced level of protection for female employees in Beijing. 


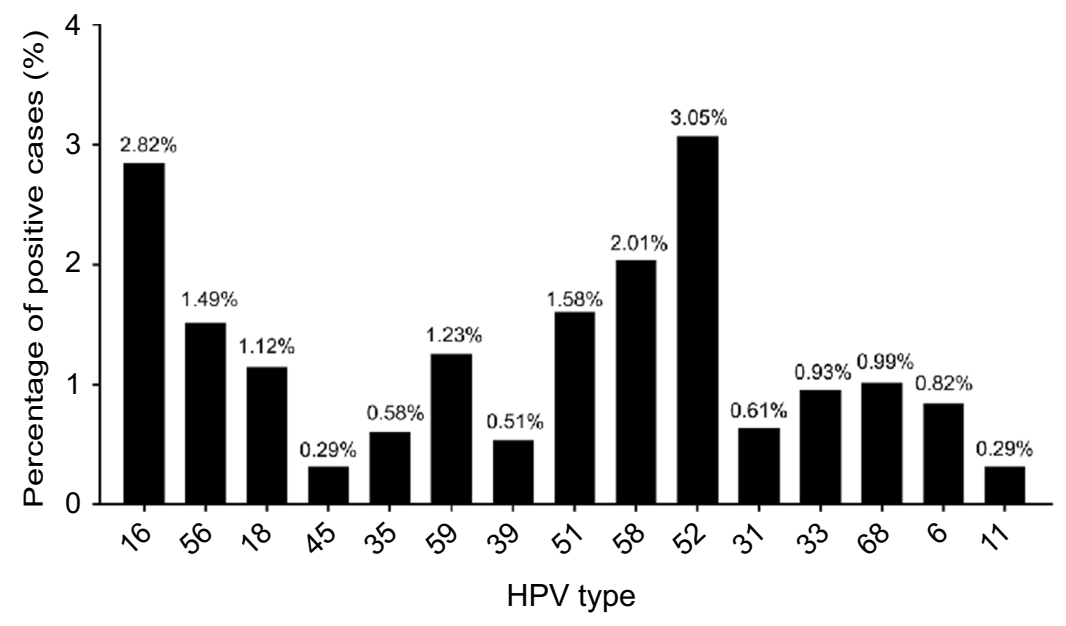

Figure 2 Distribution of human papillomavirus (HPV) subtypes in the study population.

Table 2 Findings from single-factor analysis

\begin{tabular}{|c|c|c|c|c|c|}
\hline & & $\begin{array}{l}\text { HPV-positive } \\
(n=\mid 169)\end{array}$ & $\begin{array}{l}\text { HPV-negative } \\
(n=7 \mid 28)\end{array}$ & $\chi^{2}$ & $P$-value \\
\hline Occupation & $\begin{array}{l}\text { Personnels from authority units and } \\
\text { institutions } \\
\text { Taxi drivers } \\
\text { Factory workers } \\
\text { Sanitation workers } \\
\text { Teachers } \\
\text { Medical workers }\end{array}$ & $\begin{array}{l}832(14.11 \%) \\
31(23.48 \%) \\
7(5.22 \%) \\
121(16.26 \%) \\
112(15.05 \%) \\
66(10.23 \%)\end{array}$ & $\begin{array}{l}5066(85.89 \%) \\
101(76.52 \%) \\
127(94.78 \%) \\
623(83.74 \%) \\
632(84.95 \%) \\
579(89.77 \%)\end{array}$ & 29.73 & 0.000 \\
\hline $\begin{array}{l}\text { Menstrual } \\
\text { status }\end{array}$ & $\begin{array}{l}\text { Normal menstruation } \\
\text { Irregular menstruation } \\
\text { Menopause }\end{array}$ & $\begin{array}{l}797 \text { (13.97\%) } \\
76(13.57 \%) \\
296(14.56 \%)\end{array}$ & $\begin{array}{l}4907(86.03 \%) \\
484(86.43 \%) \\
1737(85.44 \%)\end{array}$ & 0.56 & 0.756 \\
\hline Marital status & $\begin{array}{l}\text { Single but with a history of sexual activity } \\
\text { Married }\end{array}$ & $\begin{array}{l}25(28.41 \%) \\
1144(13.94 \%)\end{array}$ & $\begin{array}{l}63(71.59 \%) \\
7065(86.06 \%)\end{array}$ & 15.07 & 0.000 \\
\hline Age (years) & $\begin{array}{l}<25 \\
25-34 \\
35-44 \\
45-54 \\
55-64 \\
\geq 65\end{array}$ & $\begin{array}{l}10 \text { (22.22\%) } \\
247 \text { (14.57\%) } \\
370 \text { (13.66\%) } \\
321 \text { (13.09\%) } \\
162 \text { (16.25\%) } \\
59(14.75 \%)\end{array}$ & $\begin{array}{l}35(77.78 \%) \\
\text { I448 (85.43\%) } \\
2338(86.34 \%) \\
2|3|(86.9 \mid \%) \\
835(83.75 \%) \\
34 \mid(85.25 \%)\end{array}$ & 9.19 & 0.102 \\
\hline
\end{tabular}

\section{The factors associated with HPV infection}

According to the results of multiple binary logistic regression analysis, we found that the OR for single women with a history of sexual activity was 2.32, suggesting that these individuals are more susceptible to the risk of HPV infection compared to married women. These findings are in agreement with those of prior studies. ${ }^{24-26}$ With the postponement of first marriage age, premarital sexual activities are on the rise in many countries, including China. ${ }^{27,28}$ Thus, single women are more likely to have multiple sex partners. ${ }^{26}$
More importantly, we found that HPV infection was significantly associated with medical worker, factory workers and taxi driver. The OR for medical workers was 0.67 , suggesting that being a medical worker may confer a protective effect against HPV infection. Indeed, there are many factors that contribute to this phenomenon. One reason may be that medical workers received medical education that can increase their awareness and knowledge on HPV prevention. Several studies have demonstrated that the overall level of knowledge on HPV prevention is adequate among health care providers, including 
Table 3 Findings from multiple binary logistic regression analysis

\begin{tabular}{|c|c|c|c|c|c|c|}
\hline & & $\beta$ & SE & Wals & OR $(95 \% \mathrm{CI})$ & $P$-value \\
\hline \multirow{5}{*}{$\begin{array}{l}\text { Occupation (reference: personnels from authority } \\
\text { units and institutions) }\end{array}$} & Taxi drivers & 0.68 & 0.21 & 10.53 & $1.98(1.31,2.99)$ & 0.001 \\
\hline & Factory workers & -1.03 & 0.39 & 6.92 & $0.36(0.17,0.77)$ & 0.009 \\
\hline & Sanitation workers & 0.20 & 0.11 & 3.49 & $\mathrm{I} .22(0.99, \mathrm{I} .5 \mathrm{I})$ & 0.062 \\
\hline & Teachers & 0.03 & 0.11 & 0.05 & $1.03(0.82,1.28)$ & 0.821 \\
\hline & Medical workers & -0.40 & 0.14 & 8.20 & $0.67(0.5 \mathrm{I}, 0.88)$ & 0.004 \\
\hline \multirow{2}{*}{$\begin{array}{l}\text { Menstrual status (reference: normal } \\
\text { menstruation) }\end{array}$} & Irregular menstruation & -0.02 & 0.14 & 0.02 & $0.98(0.76,1.28)$ & 0.896 \\
\hline & Menopause & -0.06 & 0.12 & 0.23 & $0.94(0.74,1.20)$ & 0.636 \\
\hline Marital status (reference: married) & $\begin{array}{l}\text { Single but with a history of } \\
\text { sexual activity }\end{array}$ & 0.84 & 0.26 & 10.91 & $2.32(\mathrm{I} .4 \mathrm{I}, 3.82)$ & 0.001 \\
\hline \multirow[t]{5}{*}{ Age (years) (reference: $<25$ years) } & $25-34$ & -0.32 & 0.38 & 0.71 & $0.72(0.34, I .53)$ & 0.399 \\
\hline & $35-44$ & -0.40 & 0.39 & 1.06 & $0.67(0.32,1.43)$ & 0.304 \\
\hline & $45-54$ & -0.43 & 0.39 & 1.24 & $0.65(0.30,1.39)$ & 0.266 \\
\hline & $55-64$ & -0.12 & 0.41 & 0.09 & $0.88(0.40,1.96)$ & 0.762 \\
\hline & $\geq 65$ & -0.24 & 0.42 & 0.32 & $0.79(0.34, I .8 I)$ & 0.571 \\
\hline Constant & & -1.46 & 0.38 & 14.37 & & 0.000 \\
\hline
\end{tabular}

Abbreviations: $\beta$, regression co-efficient beta; $\mathrm{SE}$, standard error.

gynecologists, nurses, medical officers and so on. ${ }^{29-33}$ Notably, $52.2 \%$ of 23 health care workers ${ }^{31}$ and $95.7 \%$ of 302 medical students ${ }^{32}$ understand that cervical cancer and HPV infection are preventable. Moreover, 36.5\% among 556 nursing students are aware of the risk factors for HPV infection. ${ }^{33}$ In addition, the OR for factory workers was 0.36 , as consistent with previous findings showing that the prevalence of HPV infection is relatively low among factory workers compared to other occupation types. ${ }^{34}$ However, the exact mechanism underlying the protective role of factory occupation remains unknown and warrants further research.

On the contrary, the OR for taxi drivers was 1.98 , indicating that the HPV infection risk of taxi drivers is $98 \%$ higher compared to other occupations. Several studies have reported that the HPV infection rate of women who worked in service industries is significantly higher than that of other occupations. This may be related to the working characteristics of the service industry, including close personnel contact, living outside the law and lack of health awareness. ${ }^{35,36}$ Notably, taxi drivers are more prone to infectious diseases, such as HIV infection ${ }^{37}$ and respiratory tract infection, ${ }^{38}$ probably due to inappropriate sexual behaviors and low socioeconomic status. ${ }^{37}$ Considering the limited research on the association between HPV infection and different types of occupation, the exact roles of this risk factor remain to be determined. Obviously, it would be interesting to know whether the sedentary and restricted work environment of taxi drivers can alter their vaginal microbiome and favor HPV infection. Nevertheless, for the occupations with higher rates of HPV infection, public education strategies to increase awareness of HPV and routine cervical cancer screening are of particular importance.

Besides, Wang et $\mathrm{al}^{8}$ reported that the age-specific prevalence rate of HPV infection displayed a "two-peak" pattern, in which the 15-19-year-old group showed the highest rate of high-risk HPV infection and 50-60-yearold group demonstrated a secondary peak. However, in the present study, we did not observe a significant relationship between age and HPV infection, possibly due to the small sample size.

\section{Limitations}

Our study has several potential limitations: (i) the number of participants from authority units and institutions might be larger compared to other groups; (ii) the younger age group (below 25 years) was not excluded, as the initiation of screening at an early age can result in an overestimation of cervical cancer risk ${ }^{39}$ and (iii) this study only examined the association of HPV infection with age, occupation, marital status and menstrual status, but not other sociodemographic and behavioral variables such as degree of education, socioeconomic status, number of sexual partners, age at first intercourse and tobacco smoking. Despite these limitations, to the best of our knowledge, this is the 
first study that investigated the cervical cancer screening results of female workers in Beijing and used multivariate logistic regression analysis to adjust confounding factors for determining the factors associated with HPV infection. Therefore, the present findings are of great importance for the prevention of cervical cancer. In the future, multicenter retrospective studies with larger sample size, age-appropriate setting and comprehensive questionnaire are needed in order to provide more valuable data.

\section{Conclusion}

In conclusion, this study reveals that HPV-52, HPV-16 and HPV-58 are the three most common HPV subtypes detected in this cervical cancer screening program. This merits concern with respect to the primary and secondary prevention of cervical cancer among female employees in Beijing. Furthermore, HPV infection is associated with occupation and marital status. Being medical and factory workers are protective factors for HPV infection, whereas taxi drivers and single women with a history of sexual activity are more susceptible to the risk of HPV infection. This necessitates an increased access to education on HPV prevention and routine screening for cervical cancer.

\section{Data sharing statement}

The datasets generated from this study are not publicly available, due to privacy concerns and ongoing researches. Data can be made available to all interested researchers upon reasonable request by contacting the corresponding author.

\section{Acknowledgments}

The authors would like to thank the Beijing Federation of Trade Unions for granting this program. The costs of conducting the Cervical Cancer Screening Program and publishing this article are granted by the Beijing Federation of Trade Unions. The sponsor had no role in study design, data analysis or manuscript writing.

\section{Author contributions}

All authors contributed to data analysis, drafting or revising the article, gave final approval of the version to be published, and agree to be accountable for all aspects of the work.

\section{Disclosure}

The authors report no conflicts of interest in this work.

\section{References}

1. Bray F, Ferlay J, Soerjomataram I, et al. Global cancer statistics 2018: GLOBOCAN estimates of incidence and mortality worldwide for 36 cancers in 185 countries. CA Cancer J Clin. 2018;68(6):394424. doi: $10.3322 /$ caac. 21492

2. Walboomers JM, Jacobs MV, Manos MM, et al. Human papillomavirus is a necessary cause of invasive cervical cancer worldwide. $J$ Pathol. 1999;189(1):12-19. doi:10.1002/(SICI)1096-9896(199909) 189:1<12::AID-PATH431>3.0.CO;2-F

3. Burd EM. Human papillomavirus and cervical cancer. Clin Microbiol Rev. 2003;16(1):1-7. doi:10.1128/CMR.16.1.1-17.2003

4. Kour P, lal M, Panjaliya R, et al. Study of the risk factors associated with cervical cancer. Biomed Pharmacol J. 2010;3:1.

5. Solomon D, Davey D, Kurman R, et al. The 2001 Bethesda System: terminology for reporting results of cervical cytology. JAMA. 2002;287(16):2114-2119. doi:10.1001/jama.287.16.2114

6. Wu J, Luo X, Wu X. Result analysis of 8463 cases of cervical cancer screening. Chin J Clin Gynecology Child Med. 2011;7(3):161-165.

7. Xu H. Value of liquid-based ultrathin cell technology in the diagnosis of cervical lesions. Chin J Maternal and Child Health. 2010;25 (34):5140-5141.

8. Wang R, Guo XL, Wisman GB, et al. Nationwide prevalence of human papillomavirus infection and viral genotype distribution in 37 cities in China. BMC Infect Dis. 2015;15(1):257. doi:10.1186/ s12879-015-0998-5

9. Kliucinskas M, Nadisauskiene RJ, Minkauskiene M. Prevalence and risk factors of HPV infection among high-risk rural and urban Lithuanian women. Gynecol Obstet Invest. 2006;62(3):173-180. doi:10.1159/000093572

10. Wei B, Li X, Qi J. Analysis of detection results of 13452 cases of HPV subtype infection. Marker Immunoassay Clin. 2013;20(3):169-171.

11. Singh S, Zhou Q, Yu Y, et al. Distribution of HPV genotypes in Shanghai women. Int J Clin Exp Pathol. 2015;8(9):11901-11908.

12. Wu S, Liao C, Huang Y, et al. Analysis of the detection results of human papillomavirus of reproductive tract in 6493 women in Guangzhou area. Chin J Pract Gynecology Obstetrics. 2011;6:453456.

13. Yang Y, Wang J, Sui X, et al. Analysis of the results of cervical cancer screening in Wuxi from 2013 to 2014. Zhonghua Yu Fang Yi Xue Za Zhi. 2016;50(5):451-454. doi:10.3760/cma.j.issn.02539624.2016.05.012

14. Wang YY, Lin W, Wu B, et al. Distribution and associated factors of high-risk HPV genotypes infection among HPV-positive women who participated cervical screening test in Shenzhen, 2014-2016, China. Zhonghua Yu Fang Yi Xue Za Zhi. 2018;52(5):480-485. doi:10.3760/ cma.j.issn.0253-9624.2018.05.006

15. Chen Z, Wang Q, Ding X, et al. Characteristics of HPV prevalence in Sichuan Province, China. Int J Gynaecol Obstet. 2015;131(3):277280. doi:10.1016/j.ijgo.2015.06.027

16. Sun ZR, Ji YH, Zhou WQ, et al. Characteristics of HPV prevalence among women in Liaoning province, China. Int J Gynaecol Obstet. 2010;109(2):105-109. 1016/j.ijgo.2009.11.026

doi:10.

17. De Sanjosé S, Diaz M, Castellsagué X, et al. Worldwide prevalence and genotype distribution of cervical human papillomavirus DNA in women with normal cytology: a meta-analysis. Lancet Infect Dis. 2007;7(7):453-459. doi:10.1016/S1473-3099(07)70158-5

18. Schiffman M, Herrero R, Desalle R, et al. The carcinogenicity of human papillomavirus types reflects viral evolution. Virology. 2005;337(1):76-84. doi:10.1016/j.virol.2005.04.002

19. Trimble CL, Piantadosi S, Gravitt P, et al. Spontaneous regression of high-grade cervical dysplasia: effects of human papillomavirus type and HLA phenotype. Clin Cancer Res. 2005;11(13):4717-4723. doi:10.1158/1078-0432.CCR-04-2599 
20. Andersson S, Safari H, Mints M, et al. Type distribution, viral load and integration status of high-risk human papillomaviruses in pre-stages of cervical cancer (CIN). $\mathrm{Br} J$ Cancer. 2005;92(12):2195-2200. doi:10.1038/sj.bjc. 6602648

21. Zhao J, Guo Z, Wang Q, et al. Human papillomavirus genotypes associated with cervical precancerous lesions and cancer in the highest area of cervical cancer mortality, Longnan, China. Infect Agent Cancer. 2017;12:8. doi:10.1186/s13027-017-0116-y

22. Lowndes CM. Vaccines for cervical cancer. Epidemiol Infect. 2006;134(1):1-12. doi:10.1017/S0950268805005728

23. Joura EA, Giuliano AR, Iversen OE, et al. A 9-valent HPV vaccine against infection and intraepithelial neoplasia in women. $N$ Engl J Med. 2015;372(8):711-723. doi:10.1056/NEJMoa1405044

24. Cotton SC, Sharp L, Seth R, et al. Lifestyle and socio-demographic factors associated with high-risk HPV infection in UK women. $\mathrm{Br} J$ Cancer. 2007;97(1):133-139. doi:10.1038/sj.bjc.6603822

25. Kahn JA, Lan D, Kahn RS. Sociodemographic factors associated with high-risk human papillomavirus infection. Obstet Gynecol. 2007;110(1):87-95. doi:10.1097/01.AOG.0000266984.23445.9c

26. Ye J. Epidemiological investigation of HPV in Zhejiang and the role of cervical cancer risk factors in HPV screening [dissertation]. Zhejiang University; 2010.

27. Wellings K, Collumbien M, Slaymaker E, et al. Sexual behaviour in context: a global perspective. Lancet. 2006;368(9548):1706-1728. doi:10.1016/S0140-6736(06)69479-8

28. Zheng Z, Zhou Y, Zheng L, et al. Sexual behaviour and contraceptive use among unmarried, young women migrant workers in five cities in China. Reprod Health Matters. 2001;9(17):118-127. doi:10.1016/ S0968-8080(01)90015-1

29. Sherman SM, Bartholomew K, Denison HJ, et al. Knowledge, attitudes and awareness of the human papillomavirus among health professionals in New Zealand. PLoS One. 2018;13(12):e0197648. doi:10.1371/journal.pone.0197648

30. Chawla PC, Chawla A, Chaudhary S. Knowledge, attitude \& practice on human papillomavirus vaccination: a cross-sectional study among healthcare providers. Indian J Med Res. 2016;144(5):741-749. doi:10.4103/ijmr.IJMR_1106_14
31. Zahedi L, Sizemore E, Malcolm S, et al. Knowledge, attitudes and practices regarding cervical cancer and screening among haitian health care workers. Int J Environ Res Public Health. 2014;11 (11):11541-11552. doi:10.3390/ijerph111111541

32. Maharajan MK, Rajiah K, Num KS, et al. Knowledge of human papillomavirus infection, cervical cancer and willingness to pay for cervical cancer vaccination among ethnically diverse medical students in Malaysia. Asian Pac J Cancer Prev. 2015;16(14):57335739. doi:10.7314/APJCP.2015.16.14.5733

33. Pelullo CP, Esposito MR, Di Giuseppe G. Human papillomavirus infection and vaccination: knowledge and attitudes among nursing students in Italy. Int J Environ Res Public Health. 2019;16:10. doi:10.3390/ijerph16101770

34. Wu RF, Dai M, Qiao YL, et al. Human papillomavirus infection in women in Shenzhen City, People's Republic of China, a population typical of recent Chinese urbanisation. Int J Cancer. 2007;121 (6):1306-1311. doi:10.1002/ijc.22726

35. Chen Z, Meng W, DU R, et al. Genotype distribution and the relative risk factors for human papillomavirus in Urumqi, China. Exp Ther Med. 2013;6(1):85-90. doi:10.3892/etm.2013.1073

36. Tang HR, Zhou YQ, Wu LN, et al. Human papillomavirus infection and cervical intraepithelial neoplasia morbidity of women from different occupations in Shenzhen city, China. Zhonghua Liu Xing Bing Xue Za Zhi. 2007;28(10):951-953.

37. Lakew Y, Tamene H. HIV related risk behaviours among taxi drivers and their assistants in Addis Ababa, Ethiopia: descriptive cross-sectional survey. BMC Public Health. 2014;14(1):330. doi:10.1186/ 1471-2458-14-330

38. Nakasone Y, Nadoyama T. Present state of respiratory tract infection prevention for taxi drivers. Jan J Infect Prev Control. 2011;26 (3):167-171. doi:10.4058/jsei.26.167

39. Landy R, Birke H, Castanon A, et al. Benefits and harms of cervical screening from age 20 years compared with screening from age 25 years. $B r \quad J$ Cancer. 2014;110(7):1841-1846. doi:10.1038/bjc.2014.65

\section{Publish your work in this journal}

Cancer Management and Research is an international, peer-reviewed open access journal focusing on cancer research and the optimal use of preventative and integrated treatment interventions to achieve improved outcomes, enhanced survival and quality of life for the cancer patient.
The manuscript management system is completely online and includes a very quick and fair peer-review system, which is all easy to use Visit http://www.dovepress.com/testimonials.php to read real quotes from published authors. 